\title{
Online Appendix: Optimal Annuitization with Stochastic Mortality and Correlated Medical Costs
}

\author{
By Felix Reichling and Kent Smetters
}

Appendix A: Proofs

\section{A1. Proof of Proposition 1}

By equation $(6), \rho_{j}(h)>r$ for all values of $h$ provided that $s_{j}(h)<1$ (some people die).

\section{A2. Proof of Proposition 2}

Inserting equation (1) into equation (3) and rearranging:

$$
\begin{aligned}
\rho_{j}\left(h^{\prime} \mid h\right) & =\frac{1+\pi_{j+1}\left(h^{\prime}\right)}{\frac{s_{j}(h)}{(1+r)} \cdot\left(1+\sum_{h^{\prime}} P\left(h^{\prime} \mid h\right) \pi_{j+1}\left(h^{\prime}\right)\right)}-1 \\
& =\frac{1+\pi_{j+1}\left(h^{\prime}\right)}{\frac{s_{j}(h)}{(1+r)} \cdot\left(1+E_{H}\left(\pi_{j+1}\left(h^{\prime}\right)\right)\right)}-1
\end{aligned}
$$

Because $|\mathcal{H}|>1$ then $\pi_{j+1}(\inf (\mathcal{H}))<E_{H}\left(\pi_{j+1}(h)\right)$. It is easy, therefore, to construct examples where $\rho_{j}\left(h^{\prime} \mid h\right)<r$, thereby violating statewise dominance. Consider, for example, a set $\mathcal{H}$ with the elements $h$ and $h^{\prime}$, where $s_{j}(h) \rightarrow 1$ and $s_{j+1}\left(h^{\prime}\right) \rightarrow 0$ (and, hence, $\pi_{j+1}\left(h^{\prime}\right) \rightarrow 0$ ). Then, we can further refine $\mathcal{H}$ so that $E_{\mathcal{H}}\left(\pi_{j+1}\left(h^{\prime}\right)\right)$ is sufficiently large, producing $\rho_{j}\left(h^{\prime} \mid h\right)<r$, because $E_{\mathcal{H}}\left(\pi_{j+1}\left(h^{\prime}\right)\right) \rightarrow \infty$ implies $\rho_{j}\left(h^{\prime} \mid h\right) \rightarrow-1$.

\section{A3. Proof of Proposition 3}

The expected annuity return for a survivor to age $j+1$ is equal to 


$$
\begin{aligned}
E\left[\rho_{j}\left(h^{\prime} \mid h\right)\right] & =\frac{1+\sum_{h^{\prime}} P\left(h^{\prime} \mid h\right) \pi_{j+1}\left(h^{\prime}\right)}{\pi_{j}(h)}-1 \\
& =\frac{\frac{(1+r) \pi_{j}(h)}{s_{j}(h)}}{\pi_{j}(h)}-1 \\
& =\frac{(1+r)}{s_{j}(h)}-1 \\
& >r
\end{aligned}
$$

if $s_{j}(h)<1$.

\section{A4. Proof of Proposition 4}

See the example given in next subsection, which contradicts a claim of generic second-order stochastic dominance.

\section{Appendix B: Robustness of YaAri's Result to Additional Market IMPERFECTIONS}

\section{B1. Transaction Costs, Moral Hazard, Social Security, Household Insurance and Uncertain Income}

A couple of other market frictions can also rotate the Iso-profit Line. The most obvious one is transaction costs. Figure B1 shows the impact from adding a proportional transaction cost $\tau$ that reduces the mortality credit, rotating the Iso-profit Line downward. In fact, if the differential transaction cost of annuities relative to bonds is so large that it actually exceeds the size of the mortality credit, then a risk-neutral agent will hold only bonds, as shown in Figure B1, where the Iso-profit Line now intersects the Budget Constraint at the 100 percent bond corner. In fact, annuitization is knife-edge (100 percent or 0 percent) in the Yaari model. Moral hazard could also rotate the Iso-profit Line if agents invest in living longer after annuitization. However, moral hazard cannot exist without annuitization; its corresponding Iso-profit Line must still intersect the budget constraint at the 100 percent annuity corner.

In fact, most commonly cited market frictions do not rotate the Iso-profit Line at all, thereby having no effect. Although social security crowds out some personal saving, the asset-annuity slope tradeoff for the remaining saving is unchanged. Insurance within marriage can reduce the level of precautionary saving, but it does not eliminate the statewise dominance of annuities for remaining saving. Uncertain income and uncertain expenses - whether correlated or not with deterministic changes in mortality probabilities - also have no impact on optimal annuitization. 


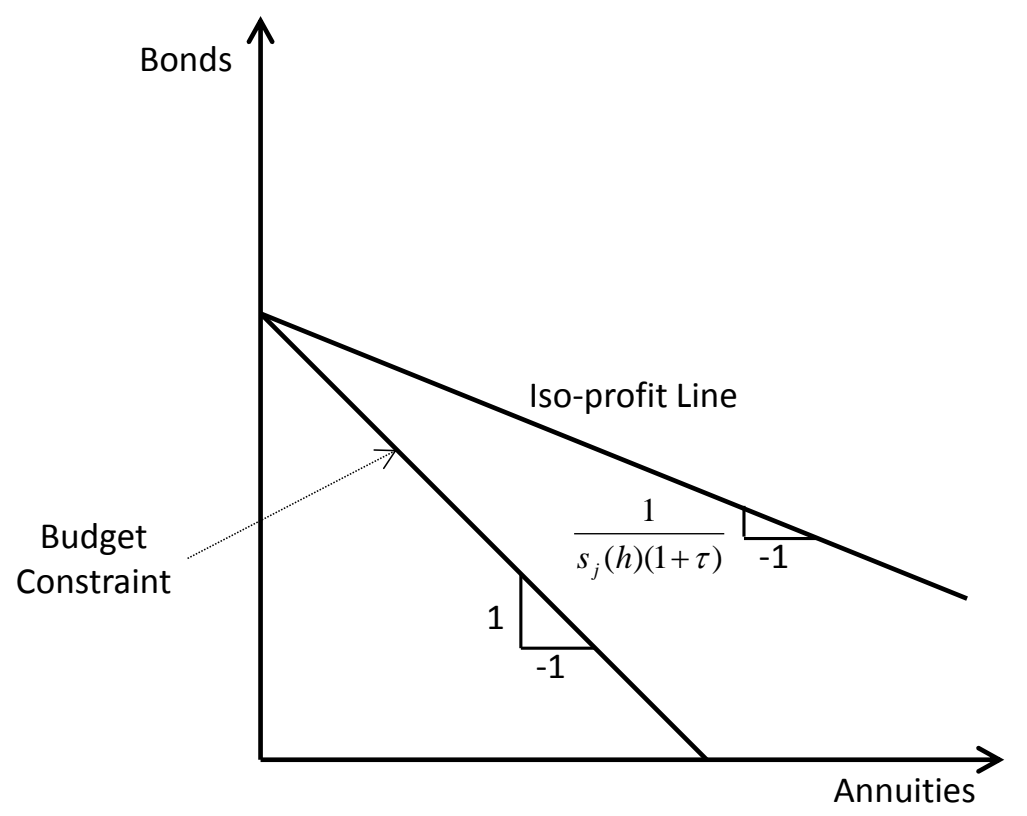

Figure B1. Optimal Annuitization in the Yaari Model with Transaction Costs

Note: Assumes that the transaction cost exceeds the value of the mortality credit.

\section{Appendix C: Robustness of Section II}

Although allowing for stochastic survival probabilities breaks the standard full annuitization result, allowing for a richer set of contracts could increase annuitization rates. We now consider a few.

\section{C1. Shorter Contracts}

In the three-period model, the annuity contract purchased at age $j$ lasts until death or age $j+2$, whichever occurs first. Suppose, however, that we replace the two-period annuity contract with a sequence of one-period contracts, the first one issued at age $j$ and the second issued at age $j+1$. There is no valuation risk with a one-period contract (formally, $\pi_{j+1}=0$ in equation (1)), and so the annuity return is simply equal to the bond yield plus any mortality credit, as in the original Yaari model. Annuities would again statewise dominate bonds.

Of course, from a welfare perspective, the value of the annuity diminishes with a shorter contract in the presence of reclassification risk. In the extreme case, with very short contracts approaching zero holding length, annuities provide no value because agents would simply rebalance right before they die. A mortality credit could not then be offered in a competitive equilibrium.

But we are more focused on annuity demand. Suppose agents also receive 
updates about their survival probabilities (and can die) at even a higher frequency than a single period. For example, the annuity contract might last for just one year, but the agent can receive information every six months. Then annuities will no longer dominate. Indeed, one can interpret our three periods as representing an interval of length $\kappa$ in total time, with each period representing time length $\kappa / 3$. Annuities will not dominate even as $\kappa \rightarrow 0$ if information innovations occur at even higher frequency.

\section{C2. A Richer Space of Mortality-Linked Contracts}

Suppose now that households could also purchase additional mortality-linked contracts that make positive or negative payments based on changes in their individual health. Naturally, we will not consider an entire set of Arrow-Debreu securities; more rigid contracts like annuities exist precisely because a full set of Arrow-Debreu securities are not available. (In other words, a security that has any resemblance to a traditional-looking annuity would be spanned by existing securities in a full Arrow-Debreu economy.) Instead, we ask, what is the minimum type of mortality-linked contract that, when combined with an annuity, would restore annuities to their statewise (or even second-order) position of dominance?

For patient households, full insurance against all other shocks would restore full annuitization when there is no asymmetric information. For impatient households, recall the imperfect annuitization can happen even without correlated costs. In this case, additional payments would also need to be made to offset the pure annuity valuation risk, which is a non-observable cost in the standard sense. Such a security would need to be fairly rich in design and be a function of characteristics of previous and current health states and age (in order to capture duration).

\section{C3. Hybrid and "Designer" Annuities}

Thus far, we have considered a "life annuity" in the traditional sense, as a contract that pays a constant amount in each state contingent on survival, as in the original Yaari model. ${ }^{1}$ Most of the annuity literature has focused on such a contract, which is our focus as well. It is straightforward, however, to construct a "hybrid annuity" with bond-like features - specifically, one that includes some non-contingent payments - that will at least weakly dominate a simple bond. By subsuming both annuity and bond types of contracts, this hybrid annuity can never do worse than either a bond or a standard annuity, purely by construction. ${ }^{2}$

\footnotetext{
${ }^{1}$ Because we have no inflation in our model, we could also interpret our annuity payments as being indexed.

${ }^{2}$ Consider, for example, the case "Low Patience" $(\beta \rightarrow 0)$ considered in Reichling and Smetters (2013). A "hybrid annuity" that paid 0.75 at ages $j+1$ and $j+2$, not contingent on actual survival, would allow the agent to consume 1.5 in both Good and Bad health states at age $j+1$. The non-contingency of the payments allows even an agent in the Bad state to borrow at the zero risk-free rate against the payment that will be made at age $j+2$, even though he or she does not survive until then. (If payments were contingent on survival, then the agent could never borrow in the Bad health state because the mortalityadjusted interest rate would be infinite.) The "hybrid annuity" would perfectly smooth consumption,
} 
Moreover, for impatient households facing no other risks, one could also create a "designer annuity" that makes contingent payments that decrease in real value with age, based on the agent's own rate of time preference. ${ }^{3}$ Finally, the demand for annuities could be altered if people could purchase an option contract that gave them the right to buy an annuity at a future date. ${ }^{4}$

\section{Appendix D: Discretization of State Space}

Total wealth at age $j, A_{j}$, is represented as one of 101 points of the wealth grid, $A_{j k}, k=0,1, \ldots, 100$. We fix point $A_{j 0}=0 ; A_{j 100}$ equals the assumed maximum wealth, and the value of $A_{j k}$ increases with $k$. For best interpolation during optimization and evaluation, the spacing between adjacent grid points is tighter at the low end of the wealth distribution, geometrically increasing values at intermediate to high wealth. Because most people's wealth increases during the early part of life, the maximum wealth $A_{j 100}$ does not have to be the same for all ages; we also allow the grid to be expanded during the computation if the maximum wealth is actually reached by a positive measure of agents.

When the optimal policy (consumption, bond saving, and annuity saving) is computed for an agent at the node $(A, \eta, h, j)$, where the indices represent wealth, productivity, health, and age, respectively, the wealth $A_{j+1}$ in the next period (age $j+1$ ) is allowed to take any positive value, rather than be limited to the values of the grid points. The value function $V_{j+1}\left(A_{j+1}, \eta_{j+1}, h_{j+1}, j+1\right)$ corresponding to that wealth is determined by interpolation between the two grid points bracketing it, for the given final productivity and health state $\left(\eta_{t+1}, h_{j+1}\right)$ and age $j+1$. To reduce the potential for non-convexities induced by limited liability (i.e., Medicaid payments that ensure positive consumption), we set the minimum level of consumption sufficiently small to produce a monotone value function in wealth, thereby avoiding the artificial incentive to take on additional risk as wealth approaches zero. Still, to be extra careful, at each state within the household's recursive problem, we execute a globally stable direct search optimization method numerous times across a wide range of different starting tuples along an appropriate mesh.

The number of nodes in the full dynamic-programming tree is $(J-20) \times m \times n \times$ $\left(k^{\max }+1\right)$, where $(J-20)$ is the age span between the minimum and maximum

as a bond does, by providing a non-contingent stream of payments. More generally, a "hybrid annuity" could reproduce any combination of bonds and traditional annuities when $0<\beta<1$.

${ }^{3}$ In the example considered earlier $(\beta \rightarrow 0)$, an annuity that paid a decreasing amount equal to 1.5 at age $j+1$ and 0 at age $j+2$ would again tie with a bond return. This decreasing-pay annuity, however, is different from a nominal annuity that makes decreasing real payments over time. Still, in practice, because a hybrid annuity is challenging to design, annuities paying a fixed nominal account could be preferred over inflation-indexed annuities.

${ }^{4}$ See, for example, Sheshinski (2007), who nicely demonstrates a welfare improvement from the introduction of this unspanned contract when annuity contracts cannot be easily rebalanced. Aside from welfare changes, the impact on the actual demand for annuities in the model herein with rebalancing is ambiguous because of the trade-off between pooling reclassification risk early in life versus the value of obtaining more information about future mortality risk that has correlated costs in our setting. Regardless, annuitization must necessarily be less than full in equilibrium in our setting. 
ages, $m$ is the number of health states, $n$ the number of productivity states, and $k^{\max }$ is the highest index of the wealth grid. We use ages from 21 to 120 , so $(J-20)=100$; as defined above, $k^{\max }=100$, and , as discussed in the paper, $m=3$ and $n=8$. Therefore, we have about $(J-20) \times m \times n \times\left(k^{\max }+1\right)=100 \times 3 \times$ $8 \times 101=242,400$ optimization problems for a single "partial equilibrium pass" of the household problem within the Gauss-Seidel routine, with each optimization problem computed up to 10 times with different starting values along a mesh. Obtaining a general equilibrium solution then typically requires 20 to 30 passes at the household problem. When the measure of agents is computed for the purposes of calculating aggregate quantities of capital and labor, a value from the continuum must be apportioned to the nearest two grid points. To preserve expected utility and the total measure, the weights given to the two points are chosen inversely proportional to the distance to them.

\section{Appendix E: Euler Equation Errors}

Using Equation (11) and assuming an interior solution the first order condition for consumption and ignoring intentional bequests $(\xi=0)$ to simplify the exposition, implies that

$$
\frac{\partial u\left(c_{j}\right)}{\partial c_{j}}=\beta s_{j}\left(h_{j}\right) E\left[\frac{\partial V_{j+1}\left(A_{j+1}, \eta_{j+1}, h_{j+1}, j+1\right)}{\partial A_{j+1}} R\left(\alpha_{j}, h_{j}, h_{j+1}\right)\right],
$$

According to the Envelope Theorem the partial derivative with respect to $A_{j}$ is

$$
\begin{gathered}
\frac{\partial V_{j}\left(A_{j}, \eta_{j}, h_{j}, j\right)}{\partial A_{j}}=\frac{\partial u\left(c_{j}\right)}{\partial A_{j}}+\beta s_{j}\left(h_{j}\right) E\left[\frac{\partial V_{j+1}\left(A_{j+1}, \eta_{j+1}, h_{j+1}, j+1\right)}{\partial A_{j}}\right], \\
\frac{\partial V_{j}\left(A_{j}, \eta_{j}, h_{j}, j\right)}{\partial A_{j}}=\beta s_{j}\left(h_{j}\right) E\left[\frac{V_{j+1}\left(A_{j+1}, \eta_{j+1}, h_{j+1}, j+1\right)}{\partial A_{j+1}} \frac{\partial A_{j+1}}{\partial A_{j}}\right]
\end{gathered}
$$

$$
\frac{\partial V_{j}\left(A_{j}, \eta_{j}, h_{j}, j\right)}{\partial A_{j}}=\beta s_{j}\left(h_{j}\right) E\left[\frac{\partial V_{j+1}\left(A_{j+1}, \eta_{j+1}, h_{j+1}, j+1\right)}{\partial A_{j+1}} R\left(\alpha_{j}, h_{j}, h_{j+1}\right)\right],
$$

Noting that the right hand side of equations (E1) and (E2) are the same, we can rewrite

$$
\frac{\partial u\left(c_{j}\right)}{\partial c_{j}}=\frac{\partial V_{j}\left(A_{j}, \eta_{j}, h_{j}, j\right)}{\partial A_{j}}
$$

This allows us to rewrite equation (E2) as 
or

$$
\frac{\partial u\left(c_{j}\right)}{\partial c_{j}}=\beta s_{j}\left(h_{j}\right) E\left[\frac{\partial u\left(c_{j+1}\right)}{\partial c_{j+1}} R\left(\alpha_{j}, h_{j}, h_{j+1}\right)\right]
$$

$$
u_{c_{j}}=\beta s_{j}\left(h_{j}\right) E\left[u_{c_{j+1}}\left(c_{j+1}\right) R\left(\alpha_{j}, h_{j}, h_{j+1}\right)\right] .
$$

Solving for consumption, we get

$$
c_{j}=u_{c_{j}}^{-1}\left\{\beta s_{j}\left(h_{j}\right) E\left[u_{c_{j+1}}\left(c_{j+1}\right) R\left(\alpha_{j}, h_{j}, h_{j+1}\right)\right]\right\}
$$

We now define the Euler Equation Error $\epsilon$ as

$$
c_{j}(1+\epsilon)=u_{c_{j}}^{-1}\left\{\beta s_{j}\left(h_{j}\right) E\left[u_{c_{j+1}}\left(c_{j+1}\right) R\left(\alpha_{j}, h_{j}, h_{j+1}\right)\right]\right\}
$$

or

$$
\epsilon=\frac{u_{c_{j}}^{-1}\left\{\beta s\left(h_{j}, j\right) E\left[u_{c_{j+1}}\left(c_{j+1}\right) R_{t}\left(\alpha_{j}, h_{j}, h_{j+1}\right)\right]\right\}-c_{j}}{c_{j}}
$$

Generally, the acceptable range of errors is $\log _{10}(\epsilon)<-3$. The Euler equation errors for people that are constrained - either because they live hand-to-mouth, or because they can annuitize only a positive fraction of their wealth - is typically larger than -3 . The errors for unconstrained people typically range from around -3 to less than -7 .

\section{Appendix F: Estimating the Complementarity Between Consumption and HEALTH}

To estimate the parameter $\lambda$ used in Section IV.B we use the Health and Retirement Study (HRS) and assign each observation to one of our health states based on their reported number of IADL and ADL impairments. ${ }^{5}$ We then calculate the average number of chronic conditions for each of our three health states, which is what Table F1 shows. Based on the Finkelstein, Luttmer and Notowidigdo (2013)'s finding that a 0.63 increase in the number of chronic conditions (a one standard deviation increase) is associated with a 10 percent to 25 percent decrease in the marginal utility of consumption, we calculate how the marginal utility of consumption would change as a result of transitions from healthy $\left(h_{1}\right)$ to impaired $\left(h_{2}\right)$, and from impaired $\left(h_{2}\right)$ to sick $\left(h_{3}\right)$. For example, when people in the HRS transition from $h_{1}$ to $h_{2}$, the number of their chronic conditions increases by 1.04, at the average. That increase is larger by a factor of $1.04 / 0.63=1.65$ than the increase of the number of chronic conditions that the estimate by Finkelstein, Luttmer and Notowidigdo (2013). is based on. Hence, we scale Finkelstein, Luttmer and Notowidigdo's reported decrease in the marginal

\footnotetext{
${ }^{5}$ Recall that our health states for retirees are defined as in Robinson (1996): Healthy state $h_{1}$ only includes people without impairments; $h_{2}$ includes people who either have only IADL impairments, or who have no more than 2 ADL impairments; $h_{3}$ includes people who have more than 2 ADL impairments or those who have some ADLs impaired and cognitive impairments).
} 
Table F1- Number of Chronic Diseases in the HRS Data

\begin{tabular}{crcc}
\hline \hline Health State & \multicolumn{1}{c}{ Obs. } & Mean & Std Dev. \\
\hline 1 & 141,779 & 1.74 & 1.56 \\
2 & 28,415 & 2.78 & 1.78 \\
3 & 10,336 & 3.29 & 1.90 \\
Total & 180,530 & 1.96 & 1.67 \\
\hline \hline
\end{tabular}

Note: Definition of health states are based on the number of functional limitations in Activities of Daily Living (ADLs) and Instrumental Activities of Daily Living (IADLs) as discussed in the main text and Robinson (1996).

Source: RAND HRS Version N data files, waves 4 (1998) through 11 (2012); Ages 50+.

utility of consumption up by a factor of 1.65 , so that the appropriate range for our model is a decrease from 16 percent to 41 percent as shown in Table F2. Based on those estimates, and the functional form of our utility function, we back out the associated value of $\lambda$ with a range from -0.26 to -0.77 . We also calculate the mid point of the estimates by taking the average of the lower and upper bounds.

\section{Appendix G: Additional Factors That Reduce Annuity Demand}

\section{G1. Management Fees}

Yearly management fees for a typical annuity range from 0.80 percent to 2.0 percent of underlying assets, not including any initial commission charges (up to 10 percent of the base) or surrender fees (around 7 percent in the first year, declining by 1 percent per year thereafter $).{ }^{6}$ In contrast, bond funds typically cost between 0.10 percent of assets (for an index of large firms) and 0.90 percent (for more specialized bonds, such as emerging markets). A differential management fee effectively reduces the mortality credit received from annuitization. We assume a differential management fee of 1 percent and ignore commissions and surrender fees. Along the intensive margin, only 12 percent of wealth is annuitized. Of that, 27 percent of retiree wealth is annuitized and 4 percent of non-retiree wealth. Along the extensive margin, 38 percent of retirees hold a positive level of annuities but only 4 percent of non-retirees hold any annuities. These results are summarized in Table G1.

\section{G2. Bequest Motives}

\section{Without Management Fees}

Without an intentional bequest motive $(\xi=0)$, all bequests are accidental and equal to about 2.6 percent of GDP in our baseline model with no management

${ }^{6}$ See The Motley Fool (2013) and CNN Money (2013). 
Table F2 - Implied Changes in the Marginal Utility of Consumption

\begin{tabular}{|c|c|c|c|c|}
\hline \multirow{3}{*}{\multicolumn{2}{|c|}{$\begin{array}{l}\text { Change in Number } \\
\text { of Chronic Conditions }\end{array}$}} & \multicolumn{3}{|c|}{$\Delta$ in $u_{c}$} \\
\hline & & Lower & Mid & Upper \\
\hline & & Bound & Point & Bound \\
\hline \multicolumn{5}{|c|}{ Finkelstein, Luttmer and Notowidigdo (2013)'s estimate } \\
\hline & 0.63 & $-10 \%$ & $-18 \%$ & $-25 \%$ \\
\hline \multicolumn{5}{|c|}{ Implied estimates based on results from Table F1 } \\
\hline$h_{1} \rightarrow h_{2}$ & 1.04 & $-16 \%$ & $-29 \%$ & $-41 \%$ \\
\hline$h_{2} \rightarrow h_{3}$ & 0.51 & $-8 \%$ & $-14 \%$ & $-20 \%$ \\
\hline Implied $\lambda$ & & -0.26 & -0.49 & -0.77 \\
\hline
\end{tabular}

Note: Shows how the range of parameter values for $\lambda$ are chosen such that the change in the marginal utility of consumption $u_{c}$ when moving between model health states is consistent with estimates by Finkelstein, Luttmer and Notowidigdo (2013) that are based on the number of chronic conditions.

fees. Empirically, however, a ratio of aggregate bequests to GDP in the range from 2.0 percent to 4.0 percent per year is certainly reasonable (Gale and Scholz, 1994; Auerbach et al., 1995; Hendricks, 2002). We therefore consider the introduction of intentional bequests $(\xi>0)$ and target a 3.3 percent bequest-GDP ratio, the point estimate of Auerbach et al. (1995). Management fees are initially set to zero. As shown in Table G1, now only 21 percent of wealth is annuitized (a decrease from the 38 percent shown in Section IV.A) and only 23 percent of households hold a positive level of annuities (a decrease from 26 percent). 


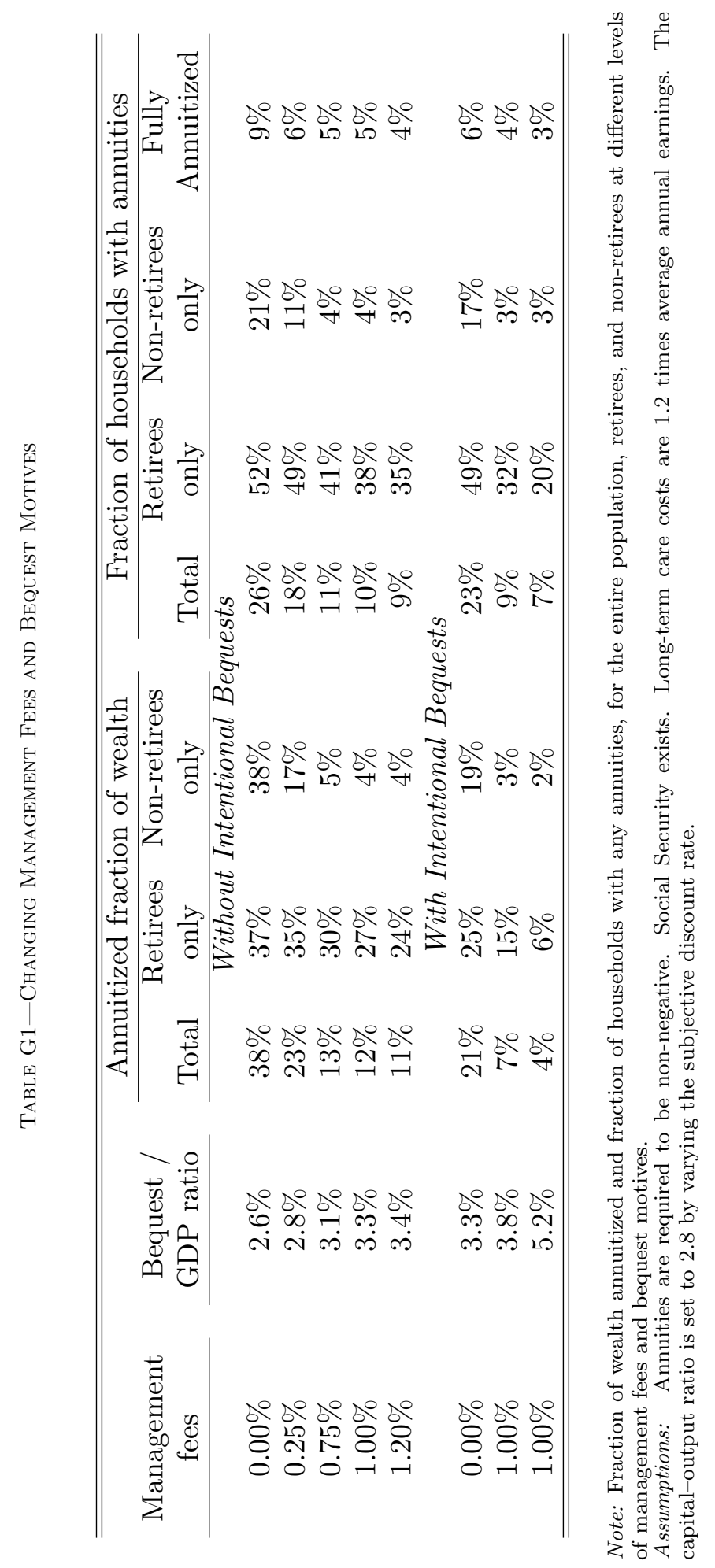




\section{With Management Fees}

We also ran simulations that combined the same level of altruism $\xi$ that produced a 3.3 percent bequest-income ratio with a 1.0 percent management fee. That combination increases the bequest-income ratio to 3.8 percent, at the upper bound of a reasonable range. In our baseline model, the amount of wealth annuitized in the economy dropped to 7 percent, with only 9 percent of households holding any annuities.

\section{With Management Fees and Uneven Bequests}

Empirically, only about 40 percent of the incidence of bequests are actually received as inheritances (Hendricks, 2002; Gale and Scholz, 1994). Some of the previous estimates of the bequest-income ratio do not clearly distinguish between bequests and inheritances. Therefore, we also ran simulations where only the bequests of the top 40 percent of income earners (as indicated by their wage at retirement) are received by younger higher-income earners. The other 60 percent is simply "thrown away" (for example, burial expenses). We target an inheritance-GDP ratio of about 2.7 percent, which produces an implied bequest-GDP ratio of around 5.2 percent. To be sure, this bequest-GDP ratio might be viewed on the high side. However, this value is actually close to the "lower bound" estimated by Gale and Scholz (1994) for households in the Survey of Consumer Finances. In particular, summing intended transfers, college expenses paid by parents, and accidental bequests, they estimate a ratio of annual flow of transfers to capital equal to 1.7 percent, which implies an annual flow to income ratio of about 4.7 percent at a capital-output ratio of 2.8. Along with a 1.0 percent differential management fee, only 4 percent of wealth is now annuitized in our model and only 7 percent of households hold any annuities (Table G1).

\section{G3. Counterparty Risk}

Beshears et al. (2012) report that the fear of default by annuity providers was another important factor discouraging survey responders from annuitizing. As the authors note, State-level guarantee funds do exist. Still, it is not unreasonable that many people might not fully trust or understand these guarantees. The guarantees are provided as a matter of policy and are not enforceable contracts. Indeed, unlike the FDIC, none of the state guarantees are even prefunded (except for NY, which historically has carried a small reserve). Instead, most states tax the policy premiums of the remaining insurers in order to fund shortfalls, with taxes typically capped at $2-3$ percent of the premium. However, since annuity manufacturing is very concentrated, ex-post assessments might fail to recover enough funds if a large insurer collapses. Moreover, not all annuities (or all parts of a given annuity contract) are necessarily covered. ${ }^{7}$ Quite reasonably, states do

\footnotetext{
${ }^{7}$ A plain vanilla fixed annuity would almost certainly be covered, but those are less common.
} 
not want to invest resources ex-ante to determine which features will be covered for all contracts sold. Instead, states typically make the determination (and produce estimates of the actuarial value of the covered features) only after failure. Hence, it is reasonable that even people who are informed about the guarantee ${ }^{8}$ might be concerned about the joint event of an insurer default and a state not paying, especially for an event that might happen decades after the purchase. Of course, people might also just misperceive the true default risk.

To examine the impact of counterparty risk, we started with our more optimistic economy (2.8 capital-output ratio) and examine what would happen if the insurer defaulted and a state paid nothing at a rate of 1 per 1,000 years $(0.1$ percent per year), implying a 15 -year default rate of around 1.5 percent. A.M. Best Co. (2014) (Exhibit 2) estimates a 15-year "impairment" rate equal to 3.65 for " $\mathrm{A}++/ \mathrm{A}+$ " rated insurers, 6.53 percent for "A/A-", 13.58 percent for "B++/B+", increasing sharply for lower rated insurers. ${ }^{9}$ However, "impairment" includes regulatory action before a default, and so these figures might be upward biased. Standards and Poors (2014) calculates a 0.49 percent weighted-average annual default rate for all U.S. insurers, across all ratings, between 1981 and 2013, for a 15-year average exceeding 7 percent. Our implied default rate, therefore, does not seem unreasonable. However, we are being a bit brutal here by assuming zero recovery value. ${ }^{10}$

Our results are reported in Table G2, where we set management fees and intentional bequests to zero. Previous models without correlated risks indicate that default risk has very little impact on annuitization (see, for example, the careful analysis by Lopes and Michaelides, 2007). Table G2 verifies that result by showing that counterparty risk affects annuitization only marginally in the Yaari version of our model without correlated risk. However, the effect of counterparty risk on annuitization is considerably larger in our model with correlated medical cost risk. Intuitively, despite the fact that the risks of a negative health shock and insurer default are uncorrelated, there is now a chance that an insurer default happens at the same time as a negative health shock occurs that dramatically lowers the annuity value, just when annuitants "really need the money" to pay for correlated uninsured costs. Even very small probabilities when interacted with very large marginal utility states can have material effects.

\footnotetext{
${ }^{8}$ While insurers and their exclusive agents are not allowed to advertise the guarantee, independent financial advisers and broker-dealers do inform their clients about the guarantees and even layer annuities across providers since the guarantee is subject to limits on the firm level rather than at the policyholder level.

${ }^{9}$ Using data from annuityadvantage.com, we estimate that about 43 percent of multi-year guaranteed deferred annuity contracts are sold by insurers with an A.M. Best Rating of A+ or higher. However, we don't have volume information per contract.

${ }^{10}$ Alternatively, our assumptions could also be interpreted as a perceived risk of default. Under that interpretation, our assumptions are likely to be very conservative relative to the survey results reported in Beshears et al. (2012), where the fear of default plays an important role among consumers. However, we are not relying on this interpretation since our analysis is intended to be normative rather than positive.
} 
Table G2-Annuitization with Potential for Default: Intensive and Extensive Margins

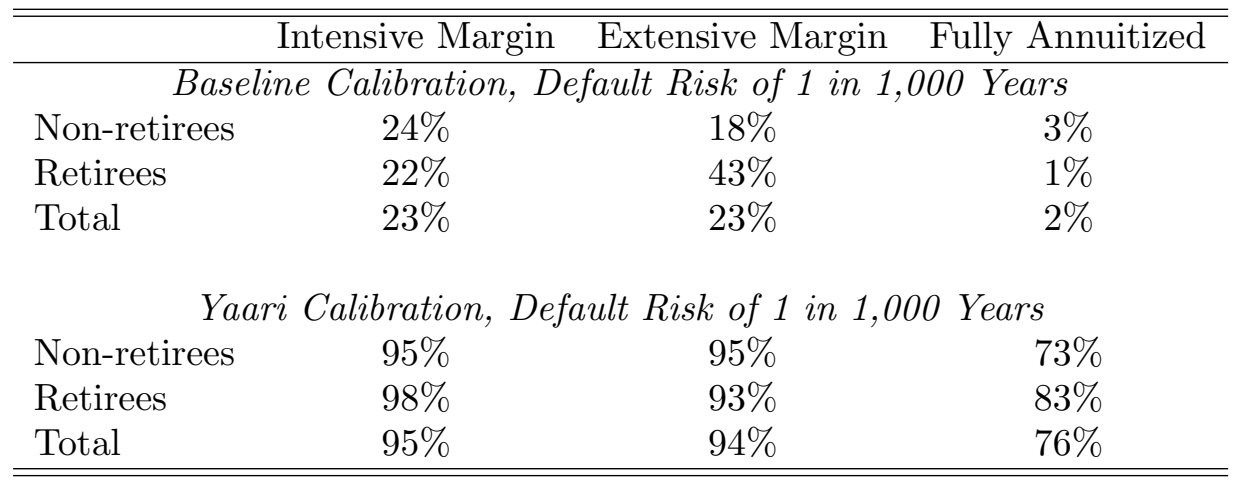

Note: Shows the amount of annuitization when the model allows for a chance of full default. A default rate of 0.1 percent corresponds to an insurer defaulting and the State not paying anything 1 time every 1,000 years, or a cumulative default probability over 30 years of 3 percent.

Assumptions: Annuities are required to be non-negative. Social Security exists. Long-term care costs are 1.2 times average annual earnings. The capital-output ratio is set to 2.8 by varying the subjective discount rate.

\section{G4. Potential Future Extensions}

We now consider three possible extensions that would likely decrease the demand for annuities even more. We tried to implement each of them but faced computational challenges or limited access to the household level of data that would allow for a clear model calibration. Therefore, we leave these extensions up to future research.

\section{Differential Transaction Costs}

Another possible extension would incorporate differential product transaction costs above the management fees considered earlier. Actual transaction fees for investing in bond funds are quite low, ranging from zero at vertically integrated broker-dealers such as Vanguard to small ticket charges at independent brokerdealers such as Schwab and Fidelity. In contrast, transaction costs for buying an insurance product such as an annuity are larger. In addition to the initial underwriting charge for determining a client's risk profile, the presence of health shocks in our model means that rebalancing would require additional underwriting in order to reduce adverse selection. These factors should further reduce the level of annuitization. Incorporating such one-sided transaction costs into our model would be computationally very challenging and is left to future research. ${ }^{11}$

\footnotetext{
${ }^{11}$ In particular, shape preservation of the value function is not well defined in higher dimension. We spent a considerable amount of effort on various approximation methods without success, as deemed by the Euler errors.
} 


\section{MORE WORKER RISK}

Recall that workers in our model were assumed to always qualify for disability insurance to partly cover their lost wages as well as private insurance to fully cover their medical costs. As a result, the only risk that workers face from health shocks in our model is from the portion of their wages that is not covered by disability. In reality, workers face risk in the form of negative health shocks that reduce future wages without becoming disabled. Workers also face uninsured medical costs in the form of low coverage or copayments. We could not find the micro-level data that would allow us to map these additional risks along the key dimensions of our model; the available data appears to be too aggregated.

\section{ASYMMETRIC INFORMATION}

Finally, recall that our simulations assume that policyholders do not hold superior information relative to insurers. As we showed earlier, while adverse selection reduces the mortality credit, it does not undermine the case for full annuitization in the Yaari model. Even an annuity with a smaller mortality credit statewise dominates bonds in the Yaari model, producing a corner solution at 100 percent annuitization. However, in the model herein with stochastic mortality probabilities and correlated costs, most households face an interior condition in their choice between annuities and bonds. As a result, any reduction in the mortality credit from asymmetric information would tend to reduce positive annuitization even more. That could result, for example, if the insurer does not want to incur the costs associated with medical underwriting. If short sales are allowed, then shorting by younger households could also be undermined if their subsequent opportunity to take a positive position is limited.

\section{REFERENCES}

A.M. Best Co. 2014. "Best's Impairment Rate and Rating Transition Study1977 to 2013." http://goo.gl/90k8g7 (accessed June 22, 2015).

Auerbach, Alan J., Jagadeesh Gokhale, Laurence J. Kotlikoff, John Sabelhaus, and David N. Weil. 1995. "The Annuitization of Americans' Resources: A Cohort Analysis." National Bureau of Economic Research Working Paper 5089.

Beshears, John, James J. Choi, David Laibson, Brigitte C. Madrian, and Stephen P. Zeldes. 2012. "What Makes Annuitization More Appealing?" National Bureau of Economic Research Working Paper 18575.

CNN Money. 2013. "Annuities-What are the disadvantages?" Ultimate Guide to Retirement, http://goo.gl/j2uG7 (accessed June 22, 2015). 
Finkelstein, Amy, Erzo Luttmer, and Matthew Notowidigdo. 2013. "What Good is Wealth Without Health? The Effect of Health on the Marginal Utility of Consumption." Journal of the European Economic Association, 11: $221-258$.

Gale, William G., and John Karl Scholz. 1994. "Intergenerational Transfers and the Accumulation of Wealth." Journal of Economic Perspectives, 8(4): 145160 .

Hendricks, Lutz. 2002. "Intended and Accidental Bequests in a Life-Cycle Economy." Department of Economics, Arizona State University Working Paper.

Lopes, Paula, and Alexander Michaelides. 2007. "Rare events and annuity market participation." Finance Research Letters, 4(2): 82-91.

Reichling, Felix, and Kent Smetters. 2013. "Optimal Annuitization with Stochastic Mortality Probabilities." National Bureau of Economic Research Working Paper 19211.

Robinson, Jim. 1996. "A Long-Term Care Status Transition Model." In The Old-Age Crisis-Actuarial Opportunities: The 1996 Bowles Symposium. Chapter 8, 72-79. Georgia State University, Atlanta.

Sheshinski, Eytan. 2007. The Economic Theory of Annuities. Princeton, New Jersey:Princeton University Press.

Standards and Poors. 2014. "2013 Annual U.S. Corporate Default Study and Rating Transitions." https://goo.gl/M7Upi0 (accessed June 22, 2015).

The Motley Fool. 2013. "Annuity Fees and Expenses." http://goo.gl/F9xvK (accessed June 22, 2015). 